PF 2019 (LXXIV): 81-92

\author{
СЛАВКА КЕРЕМИДЧИЕВА \\ Институт за български език „Проф. Любомир Андрейчин” \\ Българска академия на науките \\ бул. „Шипченски проход“ № 52, бл. 17, ет. 6 \\ София 1113 \\ tel. 359899800609 \\ e-mail: slavka_ker@abv.bg
}

\title{
ЛЕКСИКОГРАФСКО ПРЕДСТАВЯНЕ НА ДИАЛЕКТНА КУЛИНАРНА ЛЕКСИКА
}

КЛЮЧОВА ДУМА: диалектен речник, кулинария, методологически принципи.

SŁOWA KLUCZOWE: słownik gwarowy, kulinaria, zasady metodologiczne.

KEYWORDS: Dictionary of dialects, culinary, methodological principles.

\section{DIALECTAL CULINARY VOCABULARY}

\begin{abstract}
The most important methodological principles on the basis of which the Bulgarian Dialect Culinary Dictionary was composed, are presented. The Dictionary comprises a vast array of Bulgarian words and expressions related to cookery from the entire Bulgarian language territory - within and outside of the dialect continuum. This is a rich and archaic layer of national lexis that reflects Bulgarian culture and traditions in the sphere of everyday dining and during festivals and rituals alike. Chronological and geographic boundaries of the Dictionary material are traced. The conceptional plan for the structure and forming of the articles is presented: choosing of a basic version (title), defining and ordering of the meanings, words with several meanings meaning, illustrative material, localization and geographic section, etc.
\end{abstract}

През последните години в национален и международен мащаб се забелязва изключително засилен интерес към кулинарията - появиха се специализирани телевизионни канали само за готвене, почти няма телевизионен канал без собствено кулинарно предаване, в различни телевизионни формати професионални и непрофесионални готвачи се състезават за 
големи награди, създават се много игрални филми с кулинарни сюжети и пр. Публикуват се различни кулинарни книги, списания, рецептурници, книги за виното, шоколада и др., дори се издават специални празни бележници, предназначени да съберат и запазят любимите рецепти от „кухнята на баба” или „кухнята на мама”.

Като отговор на нарасналия интерес в обществото към кулинарията, а и като и възможност да бъде представен в пълнота богат и архаичен пласт от народната лексика, свързана с ежедневното и празнично хранене на българина, в Секцията за българска диалектология и лингвистична география към Института за български език при БАН се роди идеята за съставянето на Български диалектен кулинарен речник (БДКР). След компютърна обработка на богатия архивен материал и създаването на Словника на бъдещия речник започна съставянето на първите пробни речникови статии.

Най-съществените методологически принципи, въз основа на които ще бъде представена в лексикографски вид кулинарната лексика от българските диалекти, могат да бъдат накратко систематизирани по следния начин:

\section{Извори за речника}

Основата на БДКР съставя диалектен материал от Речника на Найден Геров, от други публикувани и архивни източници и от теренни проучвания, а също и от дисертационния труд на Маргарита Котева Названия, свързани с храните и тяхното приготвяне (лексикосемантична характеристика) ${ }^{1}$. Част от материала е събрана по специално изготвения от сътрудниците на секцията в края на 80-те и началото на 90-те години на XX в. нов и разширен Въпросник за събиране на диалектна лексика по тематични кръгове и групи. Материалите са ексцерпирани от архивни и публикувани източници: многотомния Сборник за народни умотворения, фолклорни и етнографски книги и сборници, регионални речници, езикови описания и краеведски проучвания и мн. др. Особено ценни са автентичните записи на живата народна реч, направени и правени и днес по време на многобройните теренни диалектоложки експедиции в различни райони на страната.

1 Praca doktorska obroniona w Sofii w 2015, autoreferat: http://ibl.bas.bg/wp-content/uploads/2015/03/Avtoreferat_MK.pdf [dostęp 11.01.2019] (od red. D.R.). 


\section{Характер на речника}

\section{1. Хронологически граници на речника}

БДКР ще съдържа народното лексикално богатство, събрано и публикувано в източници от края на XIX, XX и от началото на XXI в. до днес. Думи от по-ранни епохи няма да бъдат включвани, независимо от техния безспорен диалектен характер. Извън БДКР ще остане и лексиката от публикувани авторски текстове, чието число в последното десетилетие се увеличи многократно, тъй като в много случаи подобна лексика е съзнателно стилизирана в регионално диалектоложко отношение. След внимателен подбор е възможно да бъде включена лексика от излизащите в най-ново време на диалект регионални малки готварски книги и наръчници, както и от книги, написани изцяло на един диалект, каквито вече не са рядкост на книжния пазар.

2. По замисъл БДКР ще има диференциален характер, без обаче това определение да има абсолютен характер. Диференциалността ще бъде относителна - речникът няма да съдържа само пълни лексикални диалектизми (т.е. представящи промяната на лексикалния тип), а ще включва също и лексеми, чиито форми и значения се различават от общопознатите. В БДКР трябва да влязат и лексеми, които се отличават от книжовните по своя формален вид (т. нар. фонетични диалектизми). Ако лексемата (дори и нова) съвпада формално и семантично, но има значение (дори и само едно), различно от книжовното, то тя има своето място в речника, тъй като има семантичен обем, различен от семантичия обем на книжовния си съответник - напр. диал. тучен в значение на 'мазен, блажен' срещу книжовното тучен със значения '1. плодороден. 2. буен, сочен'.

Диференциалността ще се разбира и в смисъл на елиминиране на всички фонетични и граматични черти на микродиалектно равнище. Ще се отчитат преди всичко различията от словообразувателен и семантичен характер. Изключения могат да се направят в отделни случаи, когато напр. се отнася за особеност, която не е регулярна за конкретната диалектна система.

В БДКР не би следвало да се включват думи, напълно еднакви по формален и семантичен признак с книжовно-нормираните си съответствия. Същевременно, за да не се създаде невярната представа, че не се срещат в диалектите, те трябва да бъдат представени в речниковата статия на отделната лексема, в случай че имат, както вече казахме по-горе, поне едно значение, различно от книжовното, напр. ще се включи лексемата гра̀хче (гра̀øче) ср., умал. от грах, заради специфичното ястие та̀øце гра̀øче ‘боб, приготвен в меден или глинен съд, тас'. 
3. По своя замисъл БДКР ще представя тематичен речник, в който ще бъдат включени терминологичните диалектизми от областта на традицонната българска кулинария - храни и напитки. Предвид факта, че „кулинария” означава “готварство, изкуство за готвене и приготвяне на ястия', в обхвата на Речника няма да влязат названия на хранителни продукти, които не са преминали някаква обработка - варене, печене, пържене, мариноване, пресоване, смилане, сушене, ферментация и пр. С други думи - в него няма да бъдат открити имена на ядивни плодове и зеленчуци, които се употребяват в суров, необработен вид; напр. в БДКР няма да бъдат включени лексеми, назоваващи различните видове основни зърнени култури като ориз, пшеница, иаревица, леща и пр., но ще има речникови статии за всички видове брашна и ястия и пр., приготвени от тях след съответната студена или термична обработка. Напр. лексемата пипѐр ще бъде включена със значението си 'счукани сухи червени чушки', но не и като 'чушки - растение'. Свои речникови статии ще оформят всички подправки за ястия и напитки, тъй като те са естествените съставки за подобряването на техния вкус, вид и аромат и имат широко приложение в народната кулинария.

Извън обсега на Речника ще останат названия на различни действия и състояния на човек, свързани с храненето и пиенето като ям, плюскам, плюкам, льокам, натупа̀нча се, набру̀сен, нагмѐкан и пр., но ще има названия на различните видове кулинарни обработки като варя̀, пека̀, сгъстѝвам, запі̀ржвам, прета̀кам и пр.

Внимателно и диференцирано трябва да бъде отношението към неологизмите в БДКР. Особено важно е тяхното разграничаване от т.нар. лъжедиалектизми, от оказионализмите и индивидуализмите, тъй като, освен че всички те имат еднакво номинативно съдържание с книжовните си съответници, в повечето случаи са породени от съдържанието на контекста или екстралингвистична ситуация.

Важна група неологизми, които също трябва да бъдат лексикографски подбрани и обработени за БДКР, са напр. названията на кулинарните реалии, които нямат еднословно обозначение в диалекта, за разлика от книжовния език, в който номинацията се осъществява с една лексема (а може и описателно). Дори в състава на такива лексикално-фразеологични новообразувания да има и книжовни думи, номинативното словъсъчетание трябва да бъде отразено в речника, напр.: гу̀шки с мѐсо 'сарми с месо'.

Намерили своето място в лексикосемантичните системи на отделните диалекти, създадени по словообразувателните закони на тези системи, диалектните неологизми, които отразяват екстралингвистичните промени в съвременния народен бит и едновременно с това все по-засилващото се 
влияние на нормирания книжовен език, трябва да бъдат включени като самостоятелни речникови единици, напр.: ва̀øла, ѐклер, пюрѐ и под.

4. Замисълът е в БДКР да няма лексеми, които са засвидетелствани в писмени източници, но са без дефиниран самантичен обем, който не може да бъде определен и от контекста. По принцип те трябва да отпаднат още при първичната лексикографска обработка на архивните източници, независимо че може да имат и географско разпространение.

5. Географски граници на речника

БДКР включва словното богатство на българските диалекти от цялата българска езикова територия в нейната непрекъсваемост и извън нея. Лексиката от целия езиков континуум, както и диалектна кулинарна лексика от български говори извън него - от Украйна и Молдова (Бесарабия), Банат, от говора на кримските българи и др., влиза в речника със съответната локализация, с която е засвидетелствана в архивните и публикуваните източници. Тук вниманието ще бъде насочено към ограничаване на думите с несъмнен чужд произход, които не принадлежат към речниковия фонд на българските народни говори от XIX, XX и XXI в.

Тъй като почти липсват целенасочени системни изследвания и събрани материали от българските имиграционни центрове по света, а и поради трудностите при извършването на каквато и да е географска локализация, говорите на българската имиграция (стара и нова) в чужбина не се отразяват в речника.

Следователно, БДКР има широк географски обсег - за пръв път в българската лексикографска практика ще бъде създаден тематичен кулинарен речник, който включва цялото лексикално богатство на българските говори във и извън държавните граници, във и извън диалектния континуум.

\section{Подредба и систематизация на Речника}

Предвижда се БДКР да има традиционен азбучно-гнездови принцип на подредба. Възможно е да се обсъди и подреждането по азбучен ред в рамките на подтематични групи, т.е. в евентуалната подтематична група „Супи и чорби” лексемите да бъдат подредени по азбучен ред. Подредбата по подтематични групи има обаче една основна слабост - възможно е едни и същи лексеми да бъдат отнесени към различни подтематични групи (в зависимост от кулинарните традиции на региона), а това ще утежни излишно обема на речника. Отделно е и съображението, че речникът не би следвало да има структурата на готварска книга. 
1. Всички заглавни думи, а това са думите, които имат самостоятелни речникови статии, както и думите, които се препращат към тях, ще бъдат представени в азбучен порядък. Думи и изрази, които нямат същински речникови статии, се отнасят към самостоятелните заглавни думи.

По принцип речниковата статия ще се оглавява от една дума. Различни предложни, синтактични и други съставни изрази ще се дават под заглавните думи, усатновени съгласни обявените по-горе принципи. Видовите двойки при глаголите ще съставят самостоятелни речникови статии с препратка към глаголната форма в несвършен вид, където ще се извършва тълкуването; напр. ва̀рвам несв., ва̀рна св. Варя бързо и за кратко. и - ва̀рна св., вж. ва̀рвам.

2. Фонетични варианти

Промените в диалектната фонетична система не се отразяват в самостоятелни статии. Думите, които имат няколко фонетични варианта, се подават по азбучен ред в една статия към основния вариант. При установяването на вида на заглавната дума (основния вариант) се избира най-близката по вид до книжовната, напр.: чивермѐ, ч’увирмѐ и пр. ще са в речникова статия със заглавка чевермѐ. Възможни са и препратки към основния вариант, ако даден фонетичен вариант е твърде отдалечен от него по азбучен ред, напр. фиса̀р м. вж. виса̀р 'филия хляб’. Заглавните думи, които съществуват само в диалектите, получават такъв вид, какъвто хипотетично биха имали в книжовния език, напр.: ач'енйк, еченѝк, йайчанѝк, йа̀йченик, йайченѝк, йайчениेк', йе̂йченик '1. вид обреден великденски хляб. 2. вид ястие. 3. вид баница' и пр. ще се включат в речникова статия със заглавка яйченйк (основен вариант), към която ще бъдат изброени в скоби.

Ако няма алтернативен книжовен облик, или пък установяването на действителната форма на заглавната дума е невъзможно поради неясна етимология, то тогава диалектният облик се нормализира с книжовен правопис, напр.: бурденяेк (бурден'àк) м. 'рядко кисело мляко, размесено със суроватка; лятна овчарска храна'.

За установяването на облика на заглавката се отчита евентуалната етимология на думата и евентуалните нейни варианти в славянските езици; регистрираните до този момент различни словообразувателни промени на тази дума и нейните варианти; географското разпространение на един или друг фонетичен или словообразувателен вариант на думата в диалектите. Когато лексемата има неясна етимология и установяването на представителния облик на заглавката поражда затруднения, е възможно да се постъпи по няколко начина:

а) В случаи от типа тъганйци, тагънйци и пр. 'банички с месо' всички промени може да се дадат под една заглавка тѝганѝци, а всички 
останали варианти ще бъдат поместени в раздела за формите (в скоби след нея);

б) Ако някоя дума се явява в няколко варианта, които обаче нямат книжовни съответници, като заглавка може да се даде първият по азбучен ред облик, а останалите варианти да се включат в раздела на формите. Тези останали варанти имат свое място в азбучния ред на Речника, като

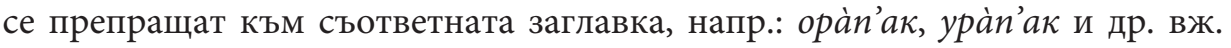
ора̀пляк 'огризка от плод'.

При представянето на диференциалната диалектна лексика може да се избере следният подход: заглавна ще бъде думата, която има най-широко разпространение (ако това може да се установи със сигурност, макар и относителна, напр., ако думата е картографирана в Българския диалектен атлас). Ако няколко форми имат приблизително еднакво разпространение, тогава за представителна може да се избере формата, която има най-ясен етимологичен облик.

При представянето на заемките внимателно трябва да се оглеждат всички техни варианти. Ако нито един от тях няма съответствие в книжовния език и етимологичният подход не дава еднозначна интерпретация, тогава вариантите се подреждат по азбучен ред в заглавката. Основният вариант на чуждиците не бива да се нормализира винаги според фонетиката на езика, от който се заема, тъй като има вероятност в нашите диалекти да не се среща никъде в изконния си вид, напр. в българския книжовен език се е наложил турският диалектен, а не книжовен (ambar) облик на лексемата хамба̀р, която се открива в нашите говори с различна фонетика и има многобройни значения - в т.ч. и 'пластична украса върху обреден хляб; вид хляб' (за разлика от само двете книжовни: '1. склад за зърнени храни; 2. дървено или железобетонно съоръжение за запазване на зърнени храни или за преработването им в насипно състояние').

Заглавната дума се подава с опростена фонетична транскрипция в основната форма, т.е. в ед.ч. Съществителните имена, които имат форми само за мн.ч., получават квалификатор само мн., а също и квалификатор обикн. мн., когато се употребяват предимно в мн.ч., напр. валк (вал'к’) м., обикн. $\mathcal{M H . ~ в а ̀ л к о в е ~ ( в а ̀ л к у в е , ~ в а л к у в и , ~ в а л ' к y ø ) ~ ' т е с т е н и ~ т о п ч е т а ' . ~ Г л а г о л н и т е ~ ф о р м и ~}$ се представят в 1 л. ед. ч. сег. вр. в несв. и св. вид. Глаголи, които се употребяват само в 3 л., не се нормализират или препращат към глаголи с пълна парадигма. Възвратните глаголи не се препращат към невъзвратните. Прилагателни имена, елови причастия от ж. и ср.р. се препращат към формата за м.р. ед.ч. Отглаголните съществителни имена не се препращат към глаголите, а оформят самостоятелна статия. 


\section{3. Словообразувателни варианти}

Различните словообразувателни варианти се представят като отделни заглавки без взаимно препращане, напр.: вйя, свѝя. Отделно се подават и различните глаголни формации от типа ва̀рвам, ва̀рувам. Изключение от този принцип са глаголите от несв. и св. вид, напр.: згра̀бувам несв. и згра̀б'е св. 'жарвам изведнъж със силен огън', при които обаче св. в. се препраща към несв. в.

Съществителните имена, които могат да се отнесат към два граматични рода, получават и два квалификатора: м. и ж. Умалителните имена се отделят от основните форми и се подават като самостоятелни заглавки.

\section{4. Омоними}

БДКР ще включва терминологична лексика, която по принцип не се характеризира с богата омонимия. Омонимите от различен етимологически произход и омонимите от общ произход се представят с арабска цифра в горния си десен край. Не се представят омоними, които тематично са извън обсега на БДКР, напр.: ку̀кла ще бъде представена без цифра като 'вид обреден хляб', ток също няма да има омоним (със значение 'харман'), а ще бъде тълкуван само като 'вид обреден хляб'. При граматичните омоними не се поставя цифра, тъй като те са разграничени или от граматическите форми, които следват след омонима, или от граматически квалификатор.

5. Причастия

За отделянето на причастията като самостоятелни речникови единици се взимат под внимание следните формални и семантични критерии:

a) причастия, които не правят изключено от формално и семантично естество, или се дават в илюстративния материал към съответния глагол, от който са образувани, или се подават в същата статия след знак $\rightarrow$.

б) причастия, чието значение се различава от значението на съответния глагол, или чиято формална и семантична връзка с глагола е отслабнала и от контекста е ясно, че те функционират като прилагателни имена, се дават като самостоятелна заглавка и без препратка към съответните глаголи.

\section{Подзаглавни думи}

Те се поместват на различни места в речниковата статия. Това са: 1. Различни съчетания, синтактични изрази и др. от типа богоро̀дична пѝта, бо̀жи кола̀ч се поместват като подзаглавки след знак (•) в края на речниковите статии със заглавна дума пѝта, кола̀ч. Те се подават в края 
на дела на значенията. Всички фразеологизми, в чийто състав влиза същ. име, се поместват под заглавка това същ. име. Фразеологизми, които нямат в състава си същ. име, се подават в статия със заглавка първия член на дадения фразеологизъм. Когато фразеологично съчетание или синтактичен израз започва с предлог или друга служебна дума, заглавката на статията е пълнозначната дума, стояща първа след предлога: на пùma, на coøpàma.

2. Съществителни имена в мн.ч., ако имат значение, различно от това на същото същ. име в ед.ч., се поместват в края на статията, чиято заглавка е същ. име в ед.ч.

\section{Оформяне на значенията}

След раздела на формите и граматичния квалификатор следва семантичният дял, който няма да има титул знач. Отделните значения се разграничават с арабски цифри. След изреждането на всички значения се представят фразеологичните съчетания, чието значение също се разкрива. Структурирането на отделните значения ще бъде извършено според следните принципи:

1. Най-напред се дават общобългарските или срещащите се в най-голям брой диалекти значения, след тях - по-рядко разпространените, а най-накрая - тясно регионалните значения.

2. Първи са преките, а след това - преносните значения.

Когато лексемата има значения, които не се отнасят до тематичния кръг „кулинарна лексика”, те не се включват в обема на речниковата статия, напр. лексемата басма̀ ще има речникова статия вероятно само с едно значение 'вид туршия, която се приготвя в запечатан с тесто глинен съд' или кы̀а само като '1. вид обреден хляб. 2. вид пластична украса върху обреден хляб'.

3. Когато се тълкуват думи, които са общи за диалектите и книжовния език, на първо място се подреждат техните общи значения дори ако това нарушава първия принцип.

4. Определяне на значението

Дефинирането на значението може да се извърши по два основни метода: синонимично или описателно. Ако семантичният обем на книжовната лексема, с която се обяснява диалектната, е широк, и само едно от книжовните значения е идентично или близко до значението на диалектната лексема, по-уместно е да се даде описателно тълкуване и след него и знак (;) да се добави книжовната дума. По принцип трябва да се избягват енциклопедичните тълкувания. 
При тълкуването на семантиката на лексемата на първо място трябва да се вземат под внимание авторските обяснения, които се съдържат в ексцерпираните материали. Ако такива обяснения липсват значението на думата трябва да се установи въз основа на контекста, в който тя е регистрирана. Ако не може да се установи значението на лексемата, тя не се включва в БДКР.

След дефинирането на значението се подава документиращ материал. Той се състои от внимателно подбрани контексти, които във възможно най-голяма степен ясно и еднозначно разкриват и илюстрират значението. За да не се утежнява статията с примери, по-нататък се посочват само районите или пунктовете, в които лексемата съществува точно с това значение. Приема се географски принцип на подреждене, който е възможно да бъде или възприетият принцип в БДА. Обобщаващ том, или в посока от юг към север.

След илюстративния материал на отделните главни значения, след квалификатор прен., се подават евентуалните преносни значения. Те също получават тълкуване, илюстративен материал и географска определеност.

5. Препратки

Думи (или форми на думи), които не са отделни заглавки, се подреждат азбучно като заглавни думи, които се препращат към речникови статии, съдържащи илюстративен материал.

\section{Стилистична характеристика на думите}

След разкриването на прякото и преносното значение на лексемата, ако е възможно, се извършва квалификация на нейния емоционално-експресивен характер, на нейната фреквенция, на историческия ѝ живот и др. под. За тези цели се използват следните бележки: нов., остар.; пренебр., ирон., руг., грубо, гальов., шег., рядко и др., използвани в практиката на Речника на българския език.

\section{Географски раздел}

Той следва след подадения илюстративен материал към значенията. Оформя се, когато материалът е толкова богат и обилен, че позволява да се направят обобщени изводи за географското разпространение на отделни думи и техните форми и значения. Определянето на географския обсег е различно от локализациите (названията на единичните населени 
пунктове), които вече са подадени по-напред в речниковата статия след документиращия значението материал. Уместно е при определянето на по-големите диалектни райони да се използват възприетите принципи на БДА. Обобщаващ том. Би било дори добре да се направят препратки към карти на атласа, които представят действителното разпространение на значенията на отделни картографирани лексеми.

С изобилния си и лексикографски интерпретиран диалектен материал БДКР ще служи като база данни за решаването на изследователски задачи в различни области на лингвистиката. Напр. този материал съставя част от излизащия многотомен Български етимологичен речник, част от него е публикувана в Старобългарския речник и продължава да се публикува в томовете на Речника на българския език. Много наши и чуждестранни учени - слависти, българисти, балканисти, лингвисти, етнолингвисти и др. ще използват в своите трудове БДКР, така както сега използват фонда на Архива като източник на автентични данни от българската диалектна територия ${ }^{2}$.

\section{Примерна речникова статия:}

аму̀р (аму̀р, хаму̀р) м. 1. Квасено тесто. Аму̀р съ ка̀зва тестото след замесването - àмyрот го̀myø ти е за сѐчене? Ряхово, Русенско. 2. Замесено тесто за хляб за една фурна. До дѐсет саàmо ва̀диме по два̀ аму̀ра лѐn. Самоковско. 3. Сладкиш, приготвен от грис, масло и захар. Сла̀mак амѝр. Ракитово, Велинградско. 4. Каша от препечено брашно, захар и олио. Ракитово, Велинградско; хаму̀р Иेдва му хаму̀ра - втасва (за тесто): След приготвянето на сирененать нарязва се на квадрати на 10-12 см и се остава да зрей. При това положение вече сирененать зрей и му идва хамура. Слатина, Ловешко

\section{Библиография}

SGP - Słownik gwar polskich. Zeszyt próbny, red. Mieczysław Karaś, WrocławWarszawa-Kraków 1964.

SNČ - Slovník nářečí českého jazyka, https://sncj.ujc.cas.cz/ [dostęp 11.01.2019]. SSN - Slovník slovenských nárečí. Ukážkový zväzok, Bratislava 1980.

2 При изготвянето на тази концепция за съставянето на БДКР е използван опитът на полските (SGP), словашките (SSN), руските (SRNG) и чешките (SNČ) учени диалектолози, както и постиженията на книжовната (РБЕ) и диалектната лексикология и лексикография у нас (по-подробно вж. Керемидчиева 2018: 113-134.) 
Славка Керемидчиева 2018, Диалекты и диалектология в Болгарии в начале XXI века. - [в]: Труды Института русского языка имени В.В. Виноградова РАН, Москва, с. 113-134.

РБЕ - Речник на българския език, т. 1 (А-Б), второ допълнено и преработено издание, София 2001.

СРНГ - Словарь русских народных говоров, вып. первый, сост. Федот П. Филин, Москва-Ленинград 1965.

\section{Streszczenie}

W artykule przedstawiono najważniejsze zasady metodologiczne, na których sporządzono Słownik kulinarny dialektu bułgarskiego. Przedstawiono chronologiczne i geograficzne granice dialektów ukazanych w słowniku. Przedstawiono koncepcję struktury i sformułowania artykułów glosariusza: wybór podstawowego nagłówka, definicja i hierarchia znaczeń, materiał ilustracyjny, lokalizacja i sekcja geograficzna itp. 